\title{
INTRODUCTION TO SYMPOSIUM ON JANIE A. CHUANG, "EXPLOITATION CREEP AND THE UNMAKING OF HUMAN TRAFFICKING LAW"
}

\author{
The Editors
}

\begin{abstract}
AJIL Unbound is pleased to introduce three comments on Janie Chuang's article "Exploitation Creep and the Unmaking of Human Trafficking Law" in the latest issue of the American Journal of International Law. In her article, Chuang demonstrates that the greatly expanded legal and policy understanding of human trafficking promoted by the US government and by influential NGOs has led to a problem that she analyzes as "exploitation creep." All forced labor is re-characterized as trafficking, even if there is no element of movement, and all trafficking is re-characterized as slavery. Chuang shows that this exploitation creep has contributed to a crossroads in the anti-trafficking movement: while intentionally fuelling the aggressive, criminal justice responses championed by the United States and well-resourced, funder-founded NGOs, "exploitation creep" also has unintentionally introduced a labor perspective into anti-trafficking law and policy. Whereas the former focuses on the accountability of individual perpetrators and the rescue of victims, the infusion of a labor-based approach exposes and targets broader structural causes. Chuang argues for building on this unintended consequence of exploitation creep to address trafficking as an outcome of weak labor and migration frameworks. Our first commentator, political scientist Clifford Bob (Duquesne University), explores whether "exploitation creep" is unique to the trafficking realm and connects Chuang's diagnosis with the concept of "framing" broadly known in sociology, communications, and political science. Second, Aziza Ahmed (Northeastern University School of Law) examines how the criminal justice approach to sex trafficking challenged by Chuang, Ahmed, and other feminist scholars "travelled with a larger set of neoliberal prescriptions for development, including efforts to address violence against women as a means to promote women's participation in markets." Our third commentator is Karen Bravo (Indiana University Robert H. McKinney School of Law), who argues that anti-trafficking efforts should go even further down the structural road than Chuang proposes. Beyond the enhancement and enforcement of mechanisms protecting labor rights, we must, among other things, confront the question whether "states' continued monopoly on the sanctioned transborder movement of humans itself creates and maintains structural vulnerability to human trafficking."
\end{abstract}

Originally published online 11 June 2015. 